\title{
A survey on formation of virtual cellular manufacturing systems (VCMSs) and related issues
}

\author{
Maryam Hamedi $^{1^{\star}}$, G. R. Esmaeilian${ }^{1}$, Napsiah Ismail$^{2}$, M. K. A. Ariffin ${ }^{2}$ \\ ${ }^{1}$ Department of Industrial Engineering, Payame Noor University, PO BOX 19395-3697, Tehran, Iran. \\ ${ }^{2}$ Department of Mechanical and Manufacturing Engineering, Faculty of Engineering, University Putra Malaysia 43400, \\ Serdang, Selangor, Malaysia.
}

Accepted 11 June, 2012

\begin{abstract}
In an environment with fluctuating demand and unpredictable parts mix compositions, the efficiency of cellular systems necessitates the use of virtual cells. Virtual cellular manufacturing systems (VCMSs) are based on a highly flexible manufacturing concept designed to improve the performance of classical cellular manufacturing systems (CMSs) and job shop manufacturing environment by creating virtual grouping the resources temporarily in the production planning and control system. The underlying concept is particularly valuable during high demands variety and variability and with increase in machines types required by parts for processing. Whereas researches on VCMSs are still in a preliminary stage, this concept has gained momentum during the last decade and a wide and diverse variety of solution techniques have been applied for solving part-machine cell formation problems in these systems. The aim of this paper is to provide a review on recent efforts and developments in the VCMSs area to make required comparisons among the published works and determine future research issues and high-impact research scopes to search more. In this study, the overview was on various criteria in detail. While already a few researchers tended to make surveys over VCMSs, some important criteria were neglected to review and consider, which this paper tried to cover them as a complementary and an updated version.
\end{abstract}

Key words: Cell formation, survey, virtual cellular manufacturing system.

\section{INTRODUCTION}

In the today's competitive market, manufacturers require well-designed layouts to improve their operations and reduce manufacturing costs. The functional layout is more robust regarding the changes in the products mix and offers a certain routing flexibility, which may improve shop performance but significantly increases the production costs because of long set-up times. Therefore, companies have encouraged utilizing types of cellular manufacturing systems (CMSs). The classical one does not satisfy the needs of companies because of its sensitivity to changing productions requirements due to their limited flexibility. In other words, classical CMSs are effective only when product families are sufficiently stable and production volumes are relatively large or easy to

\footnotetext{
*Corresponding author. E-mail: maryam.hamedi@gmail.com.
}

move. To reduce negative implications of CMSs and adapt them to turbulent environments, the concept of dynamic CMSs has been recommended in several cases. In a dynamic CMS, machines are mobile and will be reallocated as soon as production runs are competed. Dynamic manufacturing cells are useful when there are anticipated changes in products demand due to new products or new orders. In spite of keeping the positive effects of CMSs by dynamic CMSs, that system may be time-consuming and costly especially if the changes occur very frequently. Moreover, in some cases reconfiguration may become impractical or even infeasible. Hybrid CMS is one in which a functional layout and a cellular layout coexist (Shambu and Suresh, 2000). This system includes both manufacturing cells that are dedicated to specific part families, especially those with stable and high demands, and other machines arranged functionally, generally to produce parts with low and 


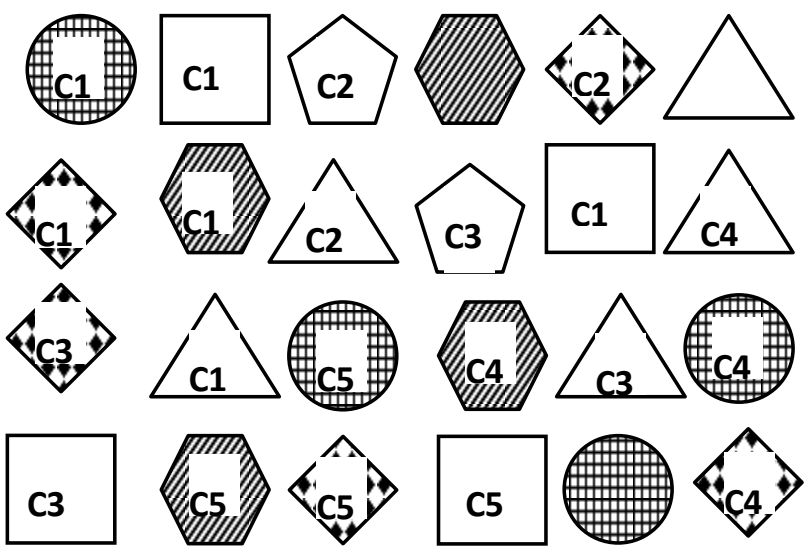

Figure 1. A general example of a formed VCMS.

erratic demands. There are many potential benefits of hybrid CMSs. The functional layout within a hybrid system is more robust to changes in products mix and demands volume. Therefore, the overall manufacturing system may be capable of responding to a wide range of demand patterns quickly and effectively, in addition to providing the benefits of manufacturing cells.

To realize the benefits normally associated with the functional layout, classical, dynamic, and hybrid CMSs, virtual cellular manufacturing systems (VCMSs) have been proposed as an alternative to volatile manufacturing environments and for functional layout settings where a conversion to the classical, dynamic, or hybrid CMSs is not feasible from a technical or financial perspective. The VCMS is a new and powerful concept including a temporarily grouping of machines, jobs and workers which instead of a physical re-allocation of machines, as in classical and dynamic CMS, aims to reduce set-up times, material handling times, and consequently lead times by grouping similar jobs in the production planning and control. Hence, flow time performance of the shop may be improved. Distinguishing such groups in the production control system offers the possibility of achieving the advantages of CMSs in non-cellular manufacturing systems. Virtual cells are most valuable when demand variability and product variety is high (Khilwani et al., 2009). In other words, due to the physical discontinuity and the dynamic aspect of configuration in the virtual cells, it is believed that uncertainty of demand and frequent changes in products mix are not significant factors affecting the efficiency of a VCMS. Figure 1 depictures a plant floor including 24 machines, which all of them have more than one copy. As it appears from the figure, five virtual cells have been formed without any machine re-arrangement.

Somewhat a VCMS resembles a process layout but in this system, machines are assigned to a family not a part. One of the most important properties of VCMSs is the machine-sharing concept. In these systems, machines are easily accessible to more than one cell for the sufficient utilization of resources in a real time, which leads to the machine overlapping. Therefore, the flexibility of virtual cells is emerged by time-sharing of machines. Moreover, a part of production costs because of machine duplication and low utilization can be reduced (Fung et al., 2008). Virtual cells are not identifiable as fixed physical grouping of machinery, but as data files and processes in a control computer. Depending on changes in demands volume and mix, virtual cells are created periodically for instance every week or every month, as new jobs accumulate during a planning period (Slomp et al., 2005).

Simultaneous with the creation of a virtual cell, a cell controller is also created. The dynamic property of a virtual cell controller guarantees that new optimal virtual cells can be created for new job orders on the same shop floor with the same machines and workers by using the dynamic concept of VCMSs (Sarker and Li, 2001). When the job mixes change, a VCMS only requires logical reconfiguration of workstations in the virtual cell controller. Physical reconfiguration of workstations is not needed in forming new manufacturing cells. In addition, the workstations are not physically locked up in a particular manufacturing cell, as in the case of classical CMSs, but can be allocated to process other jobs as long as there are sufficient residual capacities.

Several unique industrial applications have been discussed in the literature for VCMSs. In situations where ideal layouts are infeasible, a VCMS can be used to improve the system. For example, implementing group technology (GT) and CMS may be infeasible to small firms but through a VCMS, small companies can utilize the benefits of these systems without significant organizational times and new investments or rearrangements costs (Suresh and Slomp, 2005a). Moreover, a VCMS can be useful to create a test-bed for the assessment of the feasibility of layout changes. One way of achieving good responsiveness and reconfigurability in Agile Manufacturing (AM) is by creating virtual cells in which resources can be dynamically configured and reconfigured usually without having to physically rearrange the facility layout in response to changes in products demand and variety (Fung et al., 2008). Sarker and Li (2001) summarized several important assumptions in VCMSs as follows:

1) Mostly, each machine type has more than one copy available in the job shop.

2) Each component has alternative options to start from and finish at a machine to fulfil the operations sequence and precedence.

3) The system operates in a just-in-time mode.

4) Material handling costs are assumed and are embedded in travel times.

5) The operations sequence of a job only specifies the sequence and type of machines needed. The routings of the job are decided during the creation of the virtual cell.

6) Once a virtual cell is created for a job, every part of the 
job should be processed in that virtual cell unless some unexpected events such as machine breakdown and machine stoppage happen.

A VCMS does not have any limitation regarding the basic layout and can be applied to all layouts. The main requirement to apply a VCMS in a factory is that it must produce discrete products. Chemical industries and other continuous processes are in a different category (Drolet, 1989) and are not considered in VCMSs.

\section{VCMS HISTORY}

At start, National Bureau of Standards (NBS) proposed the concept of VCMSs in the 1980s in USA (McLean et al., 1982). In McLean's definition (1982), a virtual cell is not identifiable as a fixed physical grouping of workstations, but as data files and processes in a controller. Because McLean et al. (1982) were pioneers in this area, the paper tended to be conceptual and introductory and the discussion of virtual cells was more control-oriented than design-oriented. From 1980, the definition of VCMSs has evolved over times. In initial definitions of a VCMS by some researchers only answering to question of assigning parts or products to certain resources were considered, but the later definitions cover responding to a question of how people should cooperate in such a structure (Nomden et al., 2006). Whereas research on VCMSs is still in a preliminary stage, it has caught attentions of many manufacturing system engineers and researchers and gained momentum during the last decade. In general, researches which are based on the concept of VCMSs can be classified in two categories:

1) Studies dealing with the introduction, survey, comparison of VCMSs with other systems such as the functional layout and classical CMS through their performance evaluation by using the simulation or other methods, and analysing VCMSs including McLean et al. (1982), Nomden and Slomp (2003), Suresh and Slomp (2005a), Nomden et al. (2006), and Hamedi et al. (2009).

2) Studies pertaining to design of VCMSs including cell formation, sequencing, and scheduling such as researches belonging to Drolet (1989), Babu et al. (2000), Baykasoglu (2003), Ko and Egbelu (2003), Mak et al. (2005), Slomp et al. (2005), Kattan (2007), Xambre and Vilarinho (2007), and Fung et al. (2008).

Cell formation involves part family formation, machine cell organization, and finally allocation of parts families to machine cells in a manner that its performance measure is better than that of any other configuration (Khilwani et al., 2009). Sequencing is defined as determination of the order of the jobs onto each machine, and does not address timing or the internal control of the jobs within each cell. Scheduling is determination of the order of the jobs onto each machine and the determination of the precise start time and completion time of each job on each machine. In reality, most viable control schemes do not perform cell scheduling but rather employ cell sequencing (Baykasoglu, 1999). Since the initial step and the most important problem in the design of classical CMSs, dynamic CMSs, and consequently VCMSs is the cell formation, this survey discuss more on this problem rather than the sequencing and the scheduling problems.

\section{Virtual cell formation}

As mentioned earlier, cell formation consists of part family and machine grouping and forming manufacturing cells to process each part family within a virtual or physical cell with minimum travelled distances of parts or maximization of grouping efficacy. This enables any part to be processed within a cell, which has minimum interaction with other cells. Most researches in the design of VCMSs included cell formation such as Drolet (1989), Babu et al. (2000), Saad et al. (2002), Ko and Egbelu (2003), Mak et al. (2005, 2007), Slomp et al. (2005) Xambre and Vilarinho (2007), Fung et al. (2008), Khilwani et al. (2009), Rezazadeh et al. (2009). During the formation of virtual cells in manufacturing systems, the grouping of the machines is done only in the control software. The cell is not identified as a fixed physical grouping of the resources. Virtual cell formation provides a manufacturing environment, which is flexible, adaptive, and reconfigurable without considerable effort, with the support of a computerized system (Babu et al., 2000).

\section{Objectives}

There have been many efforts towards the design of manufacturing cells based on the selection of part families and machine groups, considering only a single criterion such as minimizing inter-cell movement of parts. The design of complex manufacturing systems usually involves several competing objectives that cannot easily be combined into a single objective function. Apart from the problem being single objective (one objective or some equivalent objectives) or multi-objective (different objectives), a wide range of performance objectives has been used in the related papers in the literature, ranging from financial measures through various operational measures to more abstract measures such as the cell compactness and number of exceptional elements. The most common objectives in the literature can be classified as follows:

1) Minimizing the total distance flow and consequently minimizing the material handling costs (Drolet, 1989; 
Baykasoglu, 2003; Ko and Egbelu, 2003; Mak et al., 2005; Slomp et al., 2005; Mak, et al., 2007; Xambre and Vilarinho, 2007; Fung et al., 2008).

2) Minimizing the cell overlapping which means minimization of movement of parts within the cell. It reflects the importance of dedication of cells to produce a part family, because machine sharing is one of the basic factors that enhance the batch processing time by incurring major setup time in it.

3) Maximizing the similarity coefficient during the clustering machines and parts within the cells

4) Minimizing the total lead-time, which corresponds to the total time required for completing the operation to be performed on the parts. It is the sum of the processing time, setup time, and idle time. Among three types of systems, functional, classical and virtual CMS, the setup time reduction is only applicable for classical CMSs and VCMSs.

5) Maximizing number of cells to reduce the complexity in scheduling and material control. By increasing the number of cells, machine overlapping also increases. Therefore, it is necessary to maintain a trade-off between them.

In other words, the fundamental task in the formation of VCMSs is to minimize cell overlapping with optimum number of cells that offers minimum lead-time in the production of batches, minimum total production cost, minimum throughput time, or the total flow distance of the jobs between machines. Some of other objectives, which are obvious in the literature, are minimizing the sum of the tardiness of all products (Mak et al., 2005), minimizing the total setup time (Ko and Egbelu, 2003), minimizing process description and processing time on each machine, maximizing the flexibility (Babu et al., 2000; Slomp et al., 2005), maximizing use of capacity or minimizing the load imbalances (Babu et al., 2000; Slomp et al., 2005; Xambre and Vilarinho, 2007). Mostly, the objective of VCMSs problems is to minimize either the total production cost of the job, the total throughput the time of the job or the total flow distance between machines. However, these objectives actually differ in expressions in terms of different units, and they are interconvertible to each other, that is, the optimization of one objective is equivalent to the optimization of the others (Sarker and Li, 2001).

Since the aim of this paper is reviewing more related papers in the design of VCM, in the next areas, a general summary is presented in Table 1, which covers the type of study, objectives, and major findings. This table especially can be useful to both researchers and practitioners who are interested to the VCMS concept and now are in the first steps.

\section{PRIMARY PROPERTIES}

In the cell formation problems, physical or virtual, several properties are determined based on the ideas of managers or decision makers. These properties depend on the system requirements and create several alternatives for decision makers, which should be chosen based on the available data, exist time to achieve the results, and the level of the required precision of the output. Therefore, it is evidence whenever the selected alternative presents more characteristics of the real case, outputs will have more qualities. Five of the most important properties considered as the primary properties of VCMSs have been introduced as follows.

\section{Constraining resources to form VCMSs}

Three different types of resources are considered in the various definitions of VCMSs: machines, people, and material handling equipments, but in the most cases just one resource is considered [Single Resource Constrained (SRC) systems] and the considered resource is machine. Workers, as the second important resource, have been neglected in most researches in the area of cell formation. If two constraining resources are considered for the outputs and a part can be processed only if both two constraining resources of concern are available, the system is known as dual resource constraining (DRC). If labour and machines are two considered resources, the system will be labour and machine-limited DRC (Bokhorst et al., 2004) which are usually referred to DRC.

While there is now a significant body of the literature on the job shops in DRC systems, there have been a limited number of studies on cellular and functional layouts by considering labours as the second important resource. In other words, workers have been neglected in CMSs and manufacturing cells have been considered only in terms of their respective parts and machines, and regards the machines capacities as the factors that limit production. In fact, researches on DRC settings for types of CMSs has barely begun and a limited number of studies is available in this area (Bokhorst et al., 2004). Bidanda et al. (2005) showed that there would be a significant improvement in cell performance if human skills were explicitly considered in the worker training plans and assignment strategies. Supposedly, since VCMSs are newer than classical CMSs, this shortage in VCMSs is more obvious. Given the fact that workers form the second major constraining resource and considering the substantial amount of interaction between labour skills and machining technology in a CMS and since many of the advantages associated with cellular manufacturing, classical or virtual, are derived from workers flexibility, it becomes necessary to extend the researches to DRC systems (Suresh and Slomp, 2005b).

However, research studies considering the impacts of labours are noticeably absent from the VCMSs, but there are few researches in the literature, which have considered DRC settings mostly in VCMSs and CMSs. The latest papers in this matter are discussed in this 
Table 1. A general summary on VCMSs studies.

\begin{tabular}{|c|c|c|c|c|c|c|c|c|c|c|c|c|}
\hline \multirow[b]{3}{*}{ Author's year } & \multicolumn{3}{|c|}{ Type of study } & \multicolumn{8}{|c|}{ Considered objective(s) for virtual cell formation } & \multirow[b]{3}{*}{ Major findings } \\
\hline & \multirow[b]{2}{*}{ 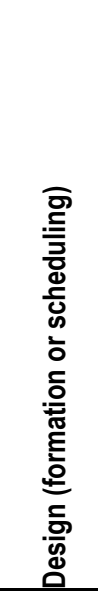 } & \multirow[b]{2}{*}{ 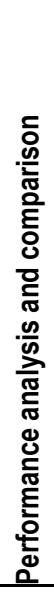 } & \multirow[b]{2}{*}{ 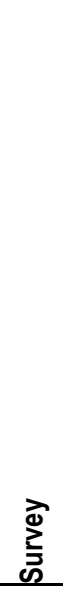 } & \multicolumn{2}{|c|}{ Number } & \multicolumn{3}{|c|}{$\begin{array}{l}\text { Minimum or } \\
\text { reduction }\end{array}$} & \multicolumn{2}{|c|}{$\begin{array}{l}\text { Maximum } \\
\text { or increase }\end{array}$} & & \\
\hline & & & & $\begin{array}{l}\frac{0}{\sigma} \\
\stackrel{\bar{\omega}}{0}\end{array}$ & $\stackrel{\underline{\underline{F}}}{\underline{\Sigma}}$ & 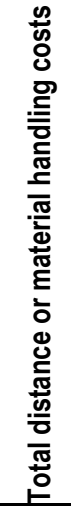 & 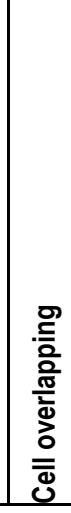 & 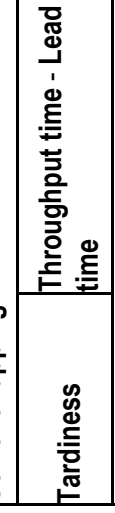 & 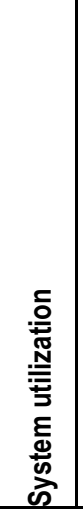 & 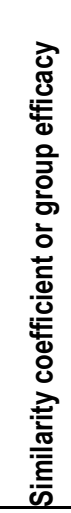 & 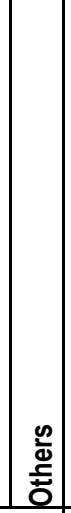 & \\
\hline McLean et al., 1982 & & $\sqrt{ }$ & & & & \multicolumn{6}{|c|}{ Control oriented } & $\begin{array}{l}\text { VMCSs have much more flexibility than classical CMSs through the sharing of } \\
\text { workstations. }\end{array}$ \\
\hline Drolet, 1989 & $\sqrt{F} \& S$ & & & $\sqrt{ }$ & & $\sqrt{ }$ & & & & & & $\begin{array}{l}\text { Superiority of VCMSs over group technology cell systems (Although VCMSs increases } \\
\text { demand on the material handling system and a more sophisticated control algorithm, but } \\
\text { potential benefits are tremendous). }\end{array}$ \\
\hline Irani et al., 1993 & $\sqrt{ }$ & & & & $\sqrt{ }$ & $\sqrt{ }$ & $\sqrt{ }$ & & & & & $\begin{array}{l}\text { Using mathematical programming models to integrate the necessary graph theoretic and } \\
\text { combinatorial optimization concepts. }\end{array}$ \\
\hline Kannan, 1997 & & $\sqrt{ }$ & & & & \multicolumn{6}{|c|}{ Simulation based } & $\begin{array}{l}\text { Presenting robustness of VCMSs to changes in the number and size of families; Showing } \\
\text { that the benefits can be obtained under setup conditions impartial to a family-oriented part } \\
\text { environment, presenting improving upon traditional job shop production and overcoming } \\
\text { the limitations of classical CMSs by VCMSs. }\end{array}$ \\
\hline Babu et al., 2000 & $\sqrt{ } F$ & & & & $\sqrt{ }$ & & $\sqrt{ }$ & & & $\sqrt{ }$ & r & $\begin{array}{l}\text { Developing a new algorithm called as "Better alternative to ROC (BETROC)" to create } \\
\text { VCMSs (the authors presented this algorithm clearly revealed its superiority over other } \\
\text { well-known algorithms, in the point of VCMSs and also in terms of its applicability in SMEs. }\end{array}$ \\
\hline M.Ratchev, 2001 & $\sqrt{F}$ & & & & $\sqrt{ }$ & & $\sqrt{ }$ & & & $\sqrt{ }$ & & A methodology to concurrent process and facility prototyping for formation of VCMSs. \\
\hline Sarker and Li, 2001 & $\sqrt{F} \& S$ & & & $\sqrt{ }$ & & & & $\sqrt{ }$ Th & & & & $\begin{array}{l}\text { Creating optimal candidates of the virtual cell with the shortest throughput time with sub- } \\
\text { optimal; alternative route(s) and throughput time(s) as the alternative candidates in case } \\
\text { some resources are restricted or are not available and scheduling for more than one job. }\end{array}$ \\
\hline Mak and Wang, 2002 & $\sqrt{F} \& S$ & & & $\sqrt{ }$ & & $\sqrt{ }$ & & & & & & $\begin{array}{l}\text { Developing an algorithm in the form of mathematical model to formulate excellent cell- } \\
\text { formation strategies and production schedules for VCMSs. }\end{array}$ \\
\hline Saad et al., 2002 & $\sqrt{F}$ & & & & $\sqrt{ }$ & & $\sqrt{ }$ & $\sqrt{ } \mathrm{Th}, \mathrm{Ta}$ & $\sqrt{ }$ & & & $\begin{array}{l}\text { Presentation how it is possible to improve performance of a CMS by reconfiguring it via } \\
\text { virtual cells. }\end{array}$ \\
\hline Ko and Egbelu, 2003 & $\sqrt{F}$ & & & & $\sqrt{ }$ & $\sqrt{ }$ & & & & & & Develop an algorithm to formation of virtual cells by use of cell sharing concept. \\
\hline Nomden and Slomp, 2003 & & $\sqrt{ }$ & & & & & & & & & & Exploring the possibilities of types of VCMSs in various layout situations. \\
\hline
\end{tabular}


Table 1. Contd.

\begin{tabular}{|c|c|c|c|c|c|c|c|c|c|c|c|}
\hline Chowdary and Praveen, 2005 & $\sqrt{ }$ & & & & $\sqrt{ }$ & $\sqrt{ }$ & & & & & $\begin{array}{l}\text { A three-phase approach for formation of VCMSs with flexibility in operations regrouping as a main } \\
\text { issue. }\end{array}$ \\
\hline Mak et al., 2005 & $\sqrt{F \& S}$ & & & $\checkmark$ & & $\sqrt{ }$ & & & & & $\begin{array}{l}\text { Developing a genetic scheduling methodology to solve the manufacturing cell formation } \\
\text { and production scheduling problems for VCMSs; specifying the types of work stations and } \\
\text { production resources that should be grouped together to form VCMSs, identifying } \\
\text { bottleneck work stations in each VCMS, determining the most appropriate rates to process } \\
\text { the assigned jobs, and specifying the times to create and terminate the VCMS. }\end{array}$ \\
\hline Slomp et al., 2005 & $\sqrt{ } \mathrm{F}$ & & & & $\sqrt{ }$ & & $\sqrt{ }$ & & $\sqrt{ }$ & $\sqrt{ }$ & $\begin{array}{l}\text { Developing an operational procedure of creating VCMS periodically through grouping } \\
\text { machines and workers in two sequential steps; promoting the novel idea of team } \\
\text { production. }\end{array}$ \\
\hline Suresh and Slomp, 2005b & & $\checkmark$ & & \multicolumn{7}{|c|}{ Simulation-base } & $\begin{array}{l}\text { Presenting that in a DRC setting and using a more comprehensive parameter range, } \\
\text { VCMSs can indeed outperform efficiently-operated flow line and CMS in certain parameter } \\
\text { ranges, characterized by moderate set-up reduction and cross training, and when there is } \\
\text { limited ability to reduce lot sizes in VCMSs and CMSs, CMSs tend to outperform both } \\
\text { VCMSs and flow line in the parameter ranges customarily advocated in GT/CMS, namely, } \\
\text { low lot sizes, adequate levels of set-up reduction, cross training of workers, and worker } \\
\text { mobility within cells. }\end{array}$ \\
\hline Nomden et al., 2006 & & & $\sqrt{ }$ & & & & & & & & Introducing future researches issues and high-impact research areas based on a review. \\
\hline Mak et al., 2007 & $\sqrt{F \&} S$ & & & $\sqrt{ }$ & & $\checkmark$ & & & & & $\begin{array}{l}\text { The developed model and algorithm perform better than the used real case in terms of } \\
\text { average workstation utilization, product completion time and system throughput, Ant Colony } \\
\text { Optimization in compare with Genetic Algorithm generates excellent final solutions in a } \\
\text { much shorter computation time. }\end{array}$ \\
\hline Xambre and Vilarinho, 2007 & $\sqrt{ } \mathrm{F}$ & & & & $\sqrt{ }$ & V & & $\sqrt{ } \mathrm{L}$ & $\checkmark$ & $\checkmark$ & $\begin{array}{l}\text { Setup reductions, (workload balancing, use of equipments for more than one family, } \\
\text { generated flow and flow simplification. using Genetic Algorithm to explore the solution } \\
\text { space in order to escape local minima and obtain a good solution. }\end{array}$ \\
\hline Fung et al., 2008 & $\sqrt{ } \mathrm{F}$ & & & & $\sqrt{ }$ & $\sqrt{ }$ & & & & 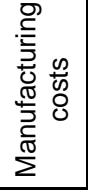 & $\begin{array}{l}\text { Selecting the appropriate resources to form the virtual cells through a multi-stage } \\
\text { methodology; Applying the proposed algorithm to AM system to facilitate the production of } \\
\text { a diverse variety of products subject to disturbances and changes during manufacturing. }\end{array}$ \\
\hline ErhanKesena et al., 2009 & & $\sqrt{ }$ & & \multicolumn{6}{|c|}{$\begin{array}{l}\text { VCM vs. CMS and Process } \\
\text { layout Simulation based }\end{array}$} & & $\begin{array}{l}\text { Showing that VCM outperforms process layout and CMA in wide range of parameter } \\
\text { settings, VCM found to be responsive demand fluctuations. VCM retains flexibility without } \\
\text { reconciling setup efficiency. }\end{array}$ \\
\hline Khilwani et al., 2009 & $\sqrt{ } \mathrm{F}$ & $\checkmark$ & & & $\sqrt{ }$ & & $\checkmark$ & $\sqrt{ } \mathbf{L}$ & $\checkmark$ & 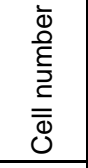 & $\begin{array}{l}\text { VCMSs are most valuable when demand variability and product variety is high, cell } \\
\text { overlapping significantly reduces the lead time by decreasing the setup time, material } \\
\text { handling time etc. increasing the number of operations on part types reduces the number of } \\
\text { cells. }\end{array}$ \\
\hline Rezazadeh et al., 2009 & $\checkmark$ & & & & $\sqrt{ }$ & $\sqrt{ }$ & & & & $\sqrt{ }$ & $\begin{array}{l}\text { Developing a comprehensive mathematical model of a dynamic VCMS and solve with } \\
\text { particle swarm optimization algorithm (LPEPSO) which presented the average gap } \\
\text { between the quality of the solution found by LPEPSO and the best solution found by the } \\
\text { branch and bound (B\&B) method is nearly } 0.77 \% \text {. }\end{array}$ \\
\hline
\end{tabular}


Table 1. Contd.

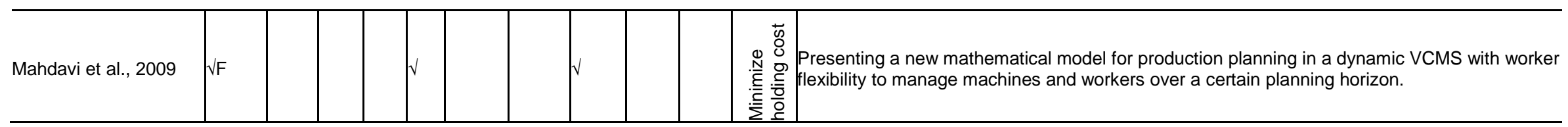

area.

Min and Shin (1993) and Suresh and Slomp (2005b) proposed cell design procedures in which the complex cell formation problem is solved in two or more phases. The last phase in both procedures concerns workforce requirements. A basic assumption in the problem formulation of Min and Shin (1993) is that workers are linked with the various parts by means of 'skill matching factors' which indicates to what extent a worker is able to produce a part. These factors are used for the optimization of the worker assignment problem. Cross-training issues were not considered in their work. Suresh and Slomp (2005) addressed various workforce requirements such as the partitioning of functionally specialized worker pools and the required additional training of workers. The need for cross-training is predetermined in their approach by setting minimum and maximum levels for the multifunctionality of workers and the redundancy of machines. They did not determine the need for cross-training analytically. Suer (1996) presented a two-phase hierarchical methodology for the operator assignment and cell loading in workerintensive manufacturing cells. Therefore, the major concern was determination of the number of workers in each cell and the assignment of workers to specific operations to maximize worker productivity. A functional arrangement of tasks was assumed in each cell without considering training and multi functionality problems. Askin and Huang (2001) focused on the relocation of workers into cells and the training needed for effective CMSs. They proposed a mixed integer goal-programming model for guiding the worker assignment and training process. The proposed model by them integrated psychological, organizational, and technical factors. They presented greedy heuristics as means to solve the problem and assumed that the required skills are cell dependent and that workers may need some additional training without considering crosstraining issues. Norman et al. (2002) presented a mixed integer programming formulation for the assignment of workers to operations in a manufacturing cell. Their formulation permitted the ability to change the skill levels of workers by providing additional training in such a way that taking the cross-training decisions was in order to balance the productivity and output quality of a manufacturing cell and the training costs. Slomp et al. (2005) presented a framework for the design of VCMSs, specifically accounting for limited availability of workers and worker skills. They proposed a goal programming formulation that first grouped jobs and machines and then assigned workers to the groups to form VCMSs. The objective was not only to use the capacity as efficiently as possible, but also to have VCMSs in places that were as independent as possible.

\section{Approach}

Before formation of manufacturing cells, the system needs to be defined. In the literature, two ways exist to define characteristics of manufacturing systems, design layouts, parts sequences and worker skills, which the first one is machine-based and the second one is capabilitybased.

In the first way, machines are considered as entities and in the second way machining capabilities include entities. In the machine-based approach, the machine-part incidence matrix is the main input. Some shortcomings have been reported for this method as follows:

1) Most times, presenting the correct route of a part on an incidence matrix is not possible because an entry in a part-machine incidence matrix indicates only whether a machine is used to process a part, not the number of times a machines is needed and in which order machines are required.

2) When the existing job shop contains many highly automated machining centres, these machines generally have a considerable amount of overlapping capability. Hence, it is not advantageous to assign a fixed machine rout for components (if it is not necessary for other reasons) which eliminates the chance of utilizing the alternative resources and flexibility available in the job shop (Baykasoglu et al., 2001)

3) The classical way of defining manufacturing systems and their capacities does not provide sufficient details in describing the shared and unique boundaries between machines. The shared 
issue should not be a machine but some function parts of a machine. Therefore, in the virtual cell formed by the corresponding methods, there are some machines in which not all the function parts need to be shared and some function parts can be shared with more cells. All these matters will influence the execution and control of the cells (Fung et al., 2008).

4) Defining processing requirements in terms of machines and designing the layout based on this consideration can certainly deteriorate production performance and it limits the flexibility (Baykasoglu, 2003).

In the second way, machine independent capability units that are known as resource elements (REs) are used to define processing requirements of parts and processing capabilities of machines and workers. The main idea of the RE approach is to define the shared and unique capabilities of machine tools. In this method, product requirements are generally defined in terms of their processing needs that each of them can be matched with any one of the capable machines. By using REs in cell formation applications, it is possible to realize the overlapping capabilities of machines and to take its advantage in configuring cells. In the RE based approach, overlapping capabilities between machines and alternative machines for part processing can be automatically taken into account while forming cells.

In the last few years, some authors encouraged to use the RE based approach to define and solve the problems in manufacturing systems. Baykasoglu et al. (2000) developed a preemptive goal-programming model to partmachine cell formation problem using a RE approach and for the solution of the model, he proposed a multiple objective tabu search based algorithm programmed in Fortran-90. Baykasoglu et al. (2001) used the RE based approach for formation of classical CMSs not virtual. They formulated a multiple objective zero-one non-linear integer-programming model. Minimizing dissimilarity between parts in each cell, minimizing total load imbalance between cells, and minimizing extra capacity requirements, while converting an existing job shop to a cellular shop, are used as objective functions to be optimized. Moreover, maximum and minimum number of parts and machines in each cell and cell independence were considered as constraints.

\section{Cell formation methods}

The cell formation problem can be extraordinarily complex because of various different production factors such as alternative process routings, operational sequences, production volumes, machine capacities, tooling times and others needed to be considered. Numerous cell formation approaches have been developed by researchers for solving the cell formation problem. These techniques were classified and reclassified a number of times by some researchers such as (Albadawi et al., 2005; Hachicha et al., 2006; Kattan, 2007; Yin and Yasuda, 2006). These methods usually differ in terms of information requirements and the final cell design. Moreover, the objectives for each method are quite different. There are many heuristic methods available in the literature to solve cell formation problems. Baykasoglu (1999) highlighted several of them including production flow analysis (PFA) as the first approaches to formation of cells which is belonging to Burbidge (1977). In this approach, part-machine groups are formed by conducting manual analysis of part routings and machines availability for operations. The majority of existing cell formation methods is matrix-based in such a way that the problem is formulated as a part-machine matrix and clustering is made by permuting the rows and columns of the 0 to 1 matrix until blocks of nonzero elements are formed around the main diagonal. Moreover, Baykasoglu (1999) introduced the rank order clustering (ROC) proposed by King (1980) the direct clustering algorithm (DCA) developed by Chan and Milner (1982), and the Bond Energy Algorithm (BEA) introduced by McCromil et al. (1972) as the most popular matrix arrangement based methods.

Similarity measures between parts or machines have been used in many cell formation methods as the basis for forming part-machine groups. The well known similarity coefficient based methods are the single linkage clustering algorithm (SLCA) by McAuley (1972) and the average linkage clustering algorithm (ALCA) introduced by Seifoddini and Wolfe (1986) Some cell formation methods use similarity coefficients in conjunction with graph theory such as Chen and Irani (1993). In such methods, machines or parts are represented by vertices of a graph in which the edges connecting these vertices represent similarity between machines or parts. The graphs are decomposed into disconnected sub-graphs to identify machine cells or part families.

The cell formation problem is mostly time consuming and known as the NP-hard ${ }^{1}$ combinational problems (Moghaddam et al., 2009). Many models and solution approaches have been developed to obtain optimal solutions in an acceptable amount of time, especially for large-sized problems. Therefore, using metaheuristic methods is unavoidable. In much of the literature focused on the design of virtual cells, applications of metaheuristic methods to solve formation of VCMSs are obviously observed. Some of the most used methods are genetic algorithms (GA) which have been used in several cell formation researchers such as Mak et al. (2005) and Xambre and Vilarinho (2007). Ant Colony (AC) optimization method used in Mak et al. (2007) and simulated annealing (SA) applied by Baykasoglu (2003). A few researchers have solved their models in the small

\footnotetext{
${ }^{1}$ NP hard (Non-deterministic Polynomial-time hard) is the complexity class of decision problem that are intrinsically harder than those are that can be solved in polynomial time.
} 
size problems by the use of mathematical and exact methods including Slopm et al. (2005). Simulation methods usually are used for some papers, which have focused on the performance of virtual cells and comparing them with other manufacturing systems.

In the majority of formulations, many practical constraints that are important for design of a proper system are not taken into account including number of machines and parts in each cell or capacity constraints. One of the possible reasons for this situation is that the technique applied for the solution of the problem does not easily allow consideration of many factors. A mathematical programming formulation is one of the most suitable alternatives for cell formation problems because such problems can integrate many important factors in the objective function and constraints. The main drawback with these techniques is the computational efficiency when the problem size gets bigger. Therefore, while formulating the problem, special considerations should be given to the types and number of variables used in the model. There is also a need to develop efficient solution procedures for solving the resulting models optimally. Modern heuristic techniques namely SA, GA and Tabu Search (TS) seem very promising from this respect (Baykasoglu and Gindy, 2000).

\section{Structure of VCMS formation}

In a system with SRC settings, the virtual cell problem basically consists of part family formation, machine cell organization and finally allocation of part family to machine cells in a manner that its performance measure is better than that of any other configuration (Khilwani et al., 2009). If labours are considered as the second resources in a DRC setting, labour cell formation is also performed through VCMS design.

Three main strategies can be considered for forming part machine cells in a SRC system.

a) Formation of machine cells first, then determination of part families

b) Formation of part families first, then determination of machine cells

c) Concurrently forming part machine cells

Two main strategies are used for forming part machine cells in DRC setting.

a) Formation of machine cells first, then assigning workers to cells

b) Formation of machine cells and workers simultaneously

In the literature, in SRC settings, part family formation and machine cell formation are generally considered and separately formulated. This increases the overall solution time of the problem and whichever is solved first, may create a restriction to obtaining independent cells. For this reason, it is better to solve the part machine cell formation and workers assignments problems concurrently. In a few researches, which have considered workers as the second resources in forming the cells, first machine- cells are formed and then workers are assigned to the formed cells. This method breaks the model into two parts and helps to reduce the solution difficulty but reduces the quality of solutions.

\section{Implementation level}

The implementation level means the production planning and the control hierarchy where virtual cells are configured. In some cases, it is a medium-term or longterm approach leading to relatively stable VCMSs configurations, labelled as master production schedule (MPS) level. At the other extreme, VMCSs are very dynamic and only exist during a single job, labelled as shop floor control (SFC) level (Nomden et al., 2006). Where the VCMs are under regular or periodical review, the implementation level is labelled as manufacturing requirements planning (MRP). Based on the time, these levels are categorized as medium-to-long term (MPS), short-to-medium term or periodical (MRP), and execution-level (SFC).

The classification of the most important papers focused on formation of VCMSs is presented in Table 2, which have been analysed based on the introduced primary properties.

\section{SECONDARY PROPERTIES}

These properties refer to status of companies when a virtual cell is being created. These properties are considered as inputs. Unlike soft properties, these properties are not optional and present realities of companies.

\section{Layout}

In the literature, virtual cells are generally generated over a functional layout such as Drolet (1989), Ko and Egbelu (2003), and Slomp et al. (2005). Kannan and Ghosh (1996a, 1996b, 1997) studied the performance of virtual cells formed over a functional layout and concluded that virtual cells could enhance production performance in volatile manufacturing environments. Similarly, Mertins et al. (2000) studied capacity assignment issues of VCMSs and formed virtual cells over a functional layout.

It has been discussed in the literature that distributed layouts are very good candidates for the implementation of VCMSs and these systems are one of the main 
Table 2. Classification of previous papers based on primary properties.

\begin{tabular}{|c|c|c|c|c|c|c|c|c|c|c|c|c|c|c|c|c|c|c|c|c|c|}
\hline \multirow[b]{2}{*}{ Author, year } & \multicolumn{3}{|c|}{ Formation method } & \multicolumn{4}{|c|}{ Grouping method } & \multicolumn{3}{|c|}{ Assigning to cell } & \multicolumn{2}{|c|}{ Approach } & \multicolumn{3}{|c|}{ VCMS independency } & \multicolumn{3}{|c|}{ Resources } & \multicolumn{3}{|c|}{ Implementation level } \\
\hline & 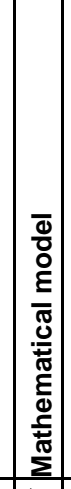 & 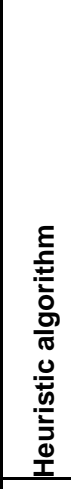 & 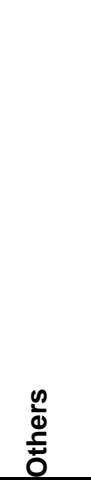 & 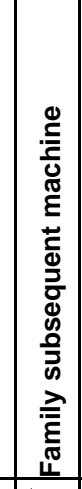 & 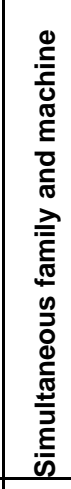 & 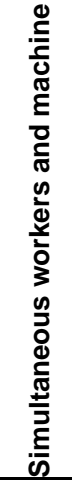 & 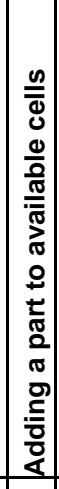 & 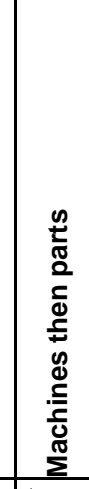 & 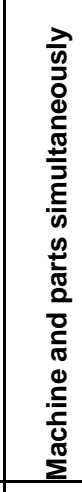 & 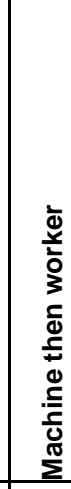 & 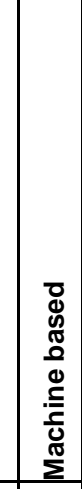 & 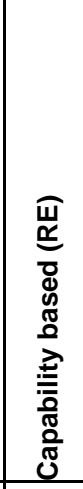 & 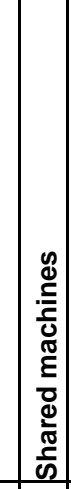 & 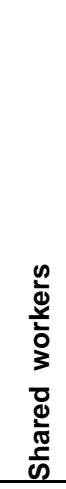 & 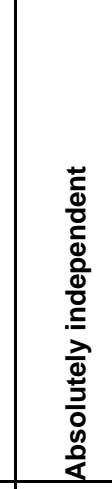 & 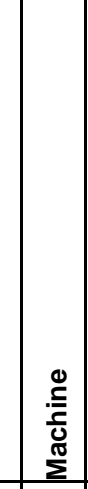 & $\begin{array}{l}0 \\
\frac{0}{0} \\
\vdots \\
0\end{array}$ & 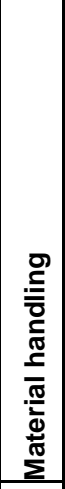 & 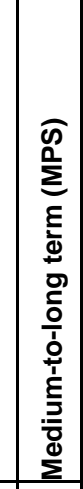 & 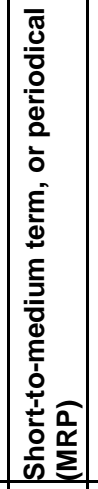 & 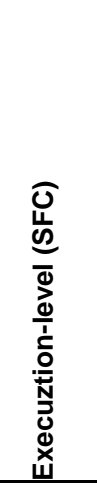 \\
\hline Irani et al., 1993 & $\sqrt{ }$ & & & $\mathrm{V}$ & & & & V & & & $\sqrt{ }$ & & & & V & $\sqrt{ }$ & V & & $\mathrm{V}$ & & \\
\hline Babu et al., 2000 & & 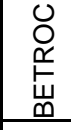 & & & & $\sqrt{ }$ & & & V & & V & & & & V & V & & & V & & \\
\hline Ratchev, 2001 & & V & & V & & & & & V & & 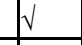 & & 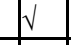 & & & $\sqrt{ }$ & & & V & & \\
\hline Sarker and Li, 2001 & & V & & & & & & & & & $\sqrt{ }$ & & $\sqrt{ }$ & & & V & & & V & & \\
\hline Mak and Wang 2002 & V & & & 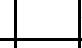 & v & & & V & & & V & & & & V & V & & & 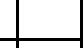 & V & \\
\hline Saad et al., 2002 & V & & & v & & & & V & & & 1 & V & & & V & $\sqrt{ }$ & & & V & & \\
\hline Ko and Egbelu, 2003 & & V & & 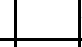 & $\mathrm{V}$ & & & 1 & $\mathrm{~V}$ & & V & & $\sqrt{ }$ & & & $\sqrt{ }$ & & & V & & \\
\hline Chowdary and Praveen, 2005 & & V & & v & & & & V & & & V & & & & V & $\sqrt{ }$ & & & $\mathrm{V}$ & & \\
\hline Mak et al., 2005 & V & & & v & & & & V & & & V & & & & & $\sqrt{ }$ & & & & V & \\
\hline$\underline{\text { Slomp et al., } 2005}$ & V & & & 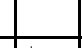 & & & & & & V & V & & $\sqrt{ }$ & & & $\sqrt{ }$ & V & & V & & \\
\hline Mak, et al., 2007 & V & & & v & & & & V & & & V & & 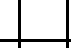 & & & $\sqrt{ }$ & & & 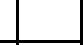 & v & \\
\hline Xambre and Vilarinho, 2007 & & V & & V & & & & V & & & V & & $\sqrt{ }$ & & & $\sqrt{ }$ & & & V & & \\
\hline Fung et al., 2008 & $\sqrt{ }$ & & & & & & & & & & & V & & & & $\sqrt{ }$ & & & v & & \\
\hline Khilwani et al., 2009 & $\sqrt{ }$ & & & & & & V & V & & & V & & V & & & $\sqrt{ }$ & & & V & & \\
\hline Rezazadeh et al., 2009 & $\sqrt{ }$ & & & & & $\sqrt{ }$ & & & & & $\sqrt{ }$ & & & & V & $\sqrt{ }$ & V & & & v & \\
\hline
\end{tabular}

application areas which distributed layouts can be implemented (Baykasoglu, 2003; Benjaafar et al., 2002). Hamedi et al. (2011) developed a comprehensive method to design weighted distributed layouts via considering machines independent capabilities by the REs approach, which caused to generation of a new type of distributed layouts named as semi-distributed layouts. Figure 2 is a sample of semi distributed 


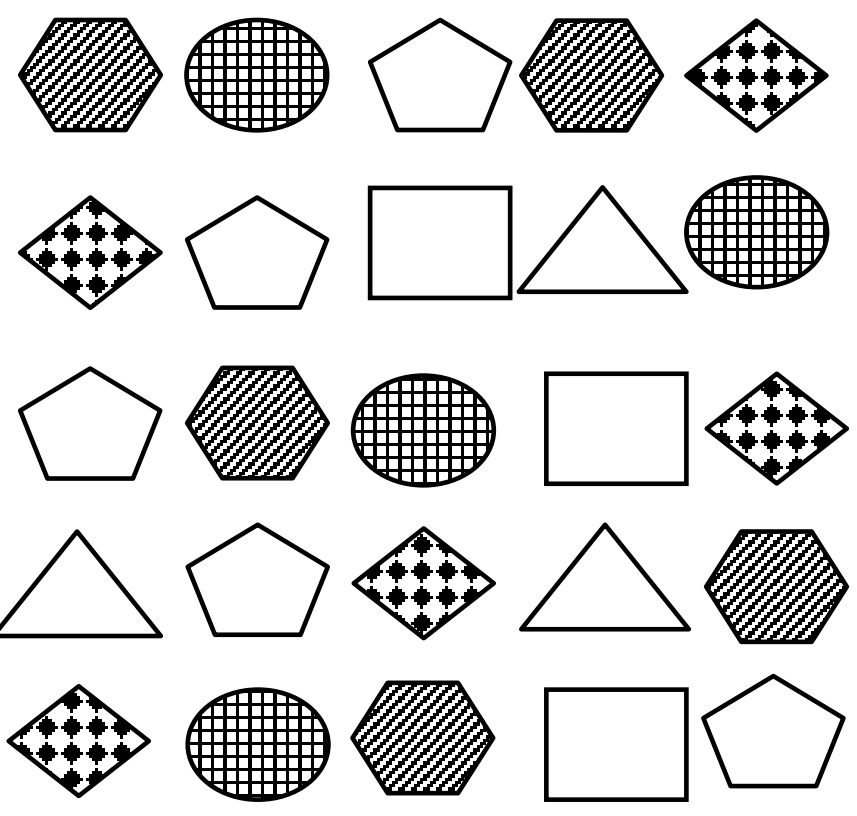

Figure 2. A semi-distributed layout (Hamedi et al., 2011).

layout taken from Hamedi et al. (2011).

If a distributed layout is used as the basic layout for formation of VCMSs such as Figure 2, the problem includes not only the assigning of families to machines and the balancing of workloads between machines of the same type, but also the distance travelled by each part and the flow complexity between machines assigned to the same cells. The advantages of distributed layouts in VCMSs have been encouraging several researchers to apply it in the manufacturing systems including Baykasoglu (2003) and Xambre and Vilarinho (2007). Moreover, few researchers used the properties of distributed layouts to arranging machines without calling that a distributed layout such as Mak et al. $(2005,2007)$. They changed the original layout to the revised layout insuch a way that in the revised layout, the workstations were widely spread over the production floor as suggested to reduce the material travelling distances in each virtual cell. The material travelling distance between two workstations is measured by using the rectangular distance between the outgoing port of the firstworkstation and the incoming part of the next

workstation.

\section{System status}

Depending on the statue of systems, the cell formation problem will be defined different but in any manufacturing systems, a general problem is discussed. Yang et al. (1994) brought out the problem as follows: $n$ components are to be processed by $m$ machine and $l$ workers within a given time horizon in such a way that given objectives are optimized. Each component involves a specific set of operations that have to be processed according to a process plan. An operation may require a deterministic or a stochastic processing time.

If the set of components is available at the beginning of the process, the problem is called static, whereas if the set of components to be processed is continuously changing over the time, the problem is called dynamic. The first case is like planning for a new system in such a way that there is not any already created workstation and several jobs that has arrived, the virtual cell controller will select a group of workstations on the production floor to form one or more new virtual cells specifically to fit the requirements of received job(s). The controller will then control the workstations in the newly formed cell(s) until completing the job(s). At the second case (dynamic), a new job enters to an available system and valid virtual cells have enough capacities. Therefore, the arrived job will be jointed with the already created virtual cells. If the available cells do not have enough capacity, by considering the available resources capacities, a new virtual cell will be created.

In a deterministic problem, all parameters are known with certainty while in a stochastic and fuzzy problem, at least one parameter is sequentially probabilistic and fuzzy.

\section{CONCLUSION}

In modern manufacturing systems such as agile and flexible manufacturing systems, there is an increasing demand for customized products, which are produced in smaller lot sizes than before. Therefore, there appear to be an increased focus on finding new methods that have the most of the strategic advantages of a job shop but also can provide some of the operational advantages of an assembly line without flexibility limitations of CMSs. Virtual cellular manufacturing systems (VCMSs) seem to be just such a method. VCMSs are a new manufacturing technology generated from the changing and dynamic marketing environment, which has gained momentum during the last decade. Although it is still a new field that needs to be explored regarding the conception, problem identification, formulation and implementation, a wide and diverse variety of solution techniques have been applied for solving the associated problems especially the cell formation because of its complexity and importance.

It is apparent from the survey preformed in this research that several studies has focused on the performance of VCMSs and its comparison with other manufacturing systems based on simulation approaches. Although a considerable quantity of the literature of VCMSs belongs to cell formation, the researchers have mostly considered machine-based formation of VCMSs 
and have not used the significant advantages of the resource element (RE) approach. The conventional machine based method to define manufacturing systems and their capacities does not provide sufficient details in describing the shared and unique boundaries between machines and workers. Whatever the capacity boundaries of each resource including machines and workers and its capabilities are well defined in conventional machine-based methods, some operations can be performed on more than one machine and using more than one worker, and some machines and workers can deal with many different operations.

Moreover, a few numbers of studies on VCMSs have considered labours as the second important resource and other researchers have ignored the importance of considering labours and have not analyzed the impact of labour flexibility, cross training, degree of centralized control, size of labour force, labour efficiency, and labour assignment rules. Due to the fact that each cell will be constrained to process because of the trained workers shortage as well as the lake of available machines, the problem of assigning workers to machines or cells is critical for classical or virtual cells in CMSs or VCMSs.

However, there is no limitation regarding basic layouts to form VCMSs over that, to reduce travelled distances by parts, distributed layouts are suitable options for those companies, which are being prepared to implement VCMSs. In the literature, there is no comprehensive model to form VCMSs over distributed layouts.

To solve cell formation problems, developing mathematical programming formulation seems to be one of the most suitable alternatives because of integrating many important factors in the objective function and constraints that usually leads to considering multiple objectives.

Cell formation problems have been known as NP-hard problem and it is difficult to obtain optimal solutions in an acceptable amount of time, especially for large-sized problems. Moreover, complexity and time consuming of cell formation as a NP-hard problem will be increased in DRC settings because of adding new variable and constraints in the model. This difficulty will be increased by considering more real factors in developed models, especially for large size problems. To solve these problems mostly metaheuristic methods including $S A$, GA, and TS were applied to solve models and achieve optimal or near optimal solutions.

Regarding the hierarchy of formation, it seems that finding an optimized solution in one stage and sending outputs to the next step does not guarantee the optimized solution for whole of the problem because the feasible solution in each step is different from the feasible solution for the integrated model. If it is assumed that this method is efficient, it cannot be used for problems in the medium or large size or even some small problems. Therefore, it will be better if the model is formulated aggregately and all variables get the optimal values simultaneously and during once running of the coded program. However, it makes problem more complex.

\section{ACKNOWLEDGMENTS}

The authors wish to thank University Putra Malaysia (UPM) for the financial support and the Department of Mechanical and Manufacturing Engineering for helping to conduct the research.

\section{REFERENCES}

Albadawi Z, Bashir HA, Chen M (2005). A mathematical approach for the formation of manufacturing cells. Comput. Ind. Eng. 48: 3-21.

Askin RG, Huang Y (2001). Forming effective worker teams for cellular manufacturing. Int. J. Prod. Res. 39(11): 2431-2451.

Babu AS, K NN, Thomas A (2000). Development of virtual cellular manufacturing systems for SMEs. Logist. Inf. Manage. 13(4): 228242.

Baykasoglu A(1999). Multiple Objective Decision Support Framework for Configuring, Loading, and Reconfiguring Manufacturing Cells. University of Nottingham, Nottingham.

Baykasoglu A (2003). Capability-based distributed layout approach for virtual manufacturing cells. Int. J. Prod. Res. 41(11): 2597-2618.

Baykasoglu A, Gindi NNZ, Cobb RC (2001). Capability based formulation and solution of multiple objective cell formation problems using simulated annealing. Integr. Manuf. Syst. 12(4): 258-274.

Baykasoglu A Gindy NN Z (2000). MOCACEF 1.0: Multiple Objective Capability Based Approach to Form Part-Machine Groups for Cellular Manufacturing Applications. Int. J. Prod. Res. 38(5): 1133-1161.

Benjaafar S, Heragu SS, Irani SA (2002). Next Generation Factory Layouts: Research Challenges and Recent Progress. Interfaces, 32(6): $58-76$

Bidanda B, Ariyawongrat $\mathrm{P}$, Needy $\mathrm{KL}$, Norman BA, Tharmmaphornphilas W (2005). Human related issues in manufacturing cell design, implementation, and operation: A review and survey. Comput. Ind. Eng. 48: 507-523.

Bokhorst JAC, Slomp J, Gaalman GJC (2004). On the who-rule in Dual Resource Constrained (DRC) manufacturing systems. Int. J. Prod. Res. 42(23): 5049-5074.

Burbidge JL (1977). A manual method for production flow analysis. Prod. Eng. 56: 34-38.

Chan HM, Milner DA (1982). Direct clustering algorithm for group formation in cellular manufacture. J. Manuf. Syst. 1: 64-76.

Chen CY, Rani SA (1993). Cluster first-sequence last heuristics for generating block diagonal forms for a machine-part matrix. Int. J. Prod. Res. 31: 2623-2647.

Chowdary BV, Praveen R (2005). Formation of Virtual Manufacturing Cells by Incorporating Flexibility. Glob. J. Flex. Syst. Manage. 6(1): 18.

Drolet JR (1989). Scheduling virtual cellular manufacturing systems. Unpublished Ph.D. thesis, Purdue University, West Lafayette, IN.

ErhanKesena S, Duran M, G"ung"orc Z, ErtanG"unerc (2009). Analyzing the behaviors of virtual cells (VCs) and traditional manufacturing systems: Ant colony optimization (ACO) based metamodels. Comput. Oper. Res. 36: 2275-2285.

Fung RYK, Wong TN, Liang F, Jiang Z (2008). A multi-stage methodology for virtual cell formation oriented agile manufacturing. International J. Adv. Manuf. Technol. 36: 798-810.

Hachicha W, Masmoudi F, Haddar Mm (2006). Principal component analysis model for machine-part cell formation problem in group technol. Paper presented at the The International Conference on Advances in Mechanical Engineering and Mechanics (ICAMEM, 2006).

Hamedi M, Ismail N, Ahmad MHM, Ariffin MKA, Esmaeilian GR (2009). A Survey on Performance and Requirements of Virtual Cellular Manufacturing versus Classical Cellular Manufacturing and Future Research Issues Paper presented at the International Advanced of 
Technol. Congress (ATCi), PWTC, Malaysia (November 3-5).

Hamedi M, Ismail Nb, Esmaeilian G, Ariffin MKA (2011). Developing a Method to Generate Semi Distributed Layout by Genetic Algorithm. Int. J. Prod. Res. 50(4): 953-975.

Irani SA, Cayalier TM, Cohen PH (1993). Virtual manufacturing cells: Exploiting layout design and intercell flows for the machine sharingproblem. Int. J. Prod. Res. 31(4): 791-810.

Kannan VR (1997). A simulation analysis of the impact of family configuration on virtual cellular manufacturing. Prod. Plan. Control, 8(1): 14-24.

Kannan VR, Ghosh S (1996a). Cellular manufacturing using virtual cells. Int. J. Oper. Prod. Manage. 16(5): 99-112.

Kannan VR, Ghosh S (1996b). A virtual cellular manufacturing approach to batch production. Decis. Sci. 27(3): 519-539.

Kattan T (2007). Cell Formation Problem- A Lagrangean Relaxation to Mathematical Programming Approach and a Linear Performance Measure., University of Windsor, Ontario, Canada.

Khilwani N, Ulutas BH, Islier AA, Tiwari MK (2009). A methodology to design virtual cellular manufacturing systems. J. Intell. Manuf. pp. 112.

King JR (1980). Machine-component grouping in production flow analysis: An approach using a rank order clustering algorithm. Int. J. Prod. Res. 18: 213-219.

Ko K-C, Egbelu PJ (2003). Virtual cell formation. Int. J Prod. Res. 41(11): 2365-2389.

Ratchev SM (2001). Concurrent Process and Facility Prototyping for Formation of Virtual Manufacturing Cells. Integr. Manuf. Syst. 12(4): 306-315.

Mahdavi I, Aalaei A, Paydar MM, Solimanpur M (2009). Production Planning and Cell Formation in Dynamic Virtual Cellular Manufacturing Systems with Worker Flexibility. IEEE ProceedingsComputational Intelligence for Modeling, Control, and Automation.

Mak KL, Lau JSK, Wang XX (2005). A genetic scheduling methodology for virtual cellular manufacturing systems: An industrial application. Int. J. Prod. Res. 43(12): 2423-2450.

Mak KL, Peng P, Wang XX, Lau TL (2007). An ant colony optimization algorithm for scheduling virtual cellular manufacturing systems. Int. J. Comput. Integr. Manuf. 20(6): 524-537.

Mak K L, Wang XX (2002). Production Scheduling and Cell Formation for Virtual Cellular Manufacturing Systems. Int. J. Adv. Manuf. Technol. 20: 144-152.

McAuley J (1972). Machine grouping for efficient production. Prod. Eng. 51: 53-57.

McCormick WT, Schweitzer RJ, White TW (1972). Problem decomposition and data reorganization by clustering techniques. Int. J. Oper. Res. 20(993-1009).

McLean CR, Bloom HM, Hopp TH (1982). In: Proceedings of the 4th IFAC/IFIP Conference on Information Control Problems in Manufacturing Technology, USA, pp. 105-111.

Mertins K, Friedland R, Rabe M (2000). Capacity assignment of virtual manufacturing cells by applying lot size harmonization. Int. J. Prod. Res. 38(17): 4385-4391.
Min H, Shin D (1993). Simultaneous formation of machine and human cells in group technol. A multiple objective approach. Int. J. Prod. Res. 31(10): 2307-2318.

Moghaddam RT, Vahed ARR, Ghodratnama A, Siadat A (2009). A simulated annealing method for solving a new mathematical model of a multi-criteria cell formation problem with capital constraints. Adv. Eng. Softw. 40(4): 268-273.

Nomden G, Slomp J (2003). The Operation of Virtual Manufacturing Cells in Various Physical Layout Situations.

Nomden G, Slomp J, Suresh NC (2006). Virtual manufacturing cells: A taxonomy of past Research and identification of future Research issues. Int. J. Flex. Manuf. Syst. 17: 71-192.

Norman $\mathrm{Ba}$, Tharmmaphornphilas W, Needy KL, Bidanday B, Warner RC (2002). Worker assignment in cellular manufacturing considering technical and human skills. Int. J. Prod. Res. 40(6): 1479-1492.

Rezazadeh H, Ghazanfari M, Sadjadi SJ, Aryanezhad MB, Makui A (2009). Linear programming embedded particle swarm optimization for solving an extended model of dynamic virtual cellular manufacturing systems. J. Appl. Res. Technol. 7(1): 83-108.

Saad SM, Baykasoglu A, Gindy NNZ (2002). An integrated framework for reconfiguration of cellular manufacturing systems using virtual cells. Prod. Plan. Control, 13(4): 381-393.

Sarker B, Li Z (2001). Job routing and operations scheduling: A network-based virtual cell formation approach. J. Oper. Res. Soc. 52: 673-681.

Seifoddini H, Wolfe PM (1986). Application of the similarity coefficient method in group technol. IIE Trans. 18(3): 271-277.

Shambu G, Suresh NC (2000). Performance of hybrid cellular manufacturing systems: A computer simulation investigation. Eur. J. Oper. Res. 120: 436-458.

Slomp J, Chowdary BV, Suresh NC (2005). Design of virtual manufacturing cells: A mathematical programming approach. Robot. Computer-Integr. Manuf. 21: 273-288.

Suer GA (1996). Optimal operator assignment and cell loading in labor intensive manufacturing cells. Comput. Ind. Eng. 26(4): 155-159.

Suresh NC, Slomp J (2005). Performance comparison of virtual cellular manufacturing with functional and cellular layouts in DRC settings. Int. J. Prod. Res. 43(5): 945-979.

Xambre AR, Vilarinho PM (2007). Virtual Manufacturing Cell Formation Problem (VMCFP) In a Distributed Layout. Paper presented at the ICPR19 - 19th International Conference on Production Research Valparaiso, Chile.

Yang T, He Z, Cho KK (1994). An effective heuristic method for generalized job shop with due dates. Comput. Ind. Eng. 26(4): 647660.

Yin Y, Yasuda K (2006). Similarity coefficient methods applied to the cell formation problem: A taxonomy and review. Int. J. Prod. Econ. 101: 329-352 